\title{
La ambliopía no afectaría el funcionamiento social, la educación, ni la salud
}

Rahi y col. BMJ 2006;332:820-825.

\section{Objetivo}

Determinar la asociación entre ambliopía y el desarrollo de diversos indicadores de salud, educativos y sociales.

Diseño

Estudio de cohortes*

Lugar

Reino Unido.

\section{Pacientes}

Comparación de 8.432 personas con visión normal en ambos ojos y $429(4,8 \%)$ con ambliopía (todos los nacidos durante una semana de 1958 y seguidos hasta los 41 años.

\section{Evaluación de factores pronósticos}

Identificaron tres categorías según la agudeza visual a los 16 años: visión normal, ambliopía leve y ambliopía moderada o grave.

\section{Medición de resultados principales}

Se evaluó la asociación de ambliopía con: educación; coordinación; mejor nivel educativo obtenido; dificultades de conducta o mala adaptación social escolar u hogareña; participación en deportes o juegos al aire libre; participación en actividades sociales; lesiones accidentales que requirieron atención hospitalaria; autoreporte de estado de salud; experiencia laboral; ocupación a los 33 años en ocupaciones "clave" para los cuales se requiere un mínimo de agudeza visual regulado por estatutos existentes en el Reino Unido; impacto sobre la clase social determinada por la ocupación, y mortalidad por todas las causas.

\section{Resultados principales}

La tabla 1 muestra los resultados principales del estudio. Solamente se encontró asociación estadísticamente significativa entre la presencia de ambliopía moderada o severa (pero no leve) y los accidentes de tránsito cuando el paciente era el conductor.

Tabla 1 Asociación entre ambliopía leve o moderado/severa y resultados en educación, sociales y de salud

\begin{tabular}{|c|c|c|c|c|}
\hline Resultados & $\begin{array}{c}\text { Visión } \\
\text { normal }(n)\end{array}$ & Grado & $n(\%)$ & $\begin{array}{l}\text { Diferencias ajustadas } \\
\text { en puntajes ([C95\%)* }\end{array}$ \\
\hline \multirow{2}{*}{$\begin{array}{l}\text { Puntaje general de capacidades } \\
\text { verbales a los } 11 \text { años }\end{array}$} & \multirow[t]{2}{*}{5526} & Leve & 184 & NS \\
\hline & & Moderado/s evera & 73 & NS \\
\hline \multirow{2}{*}{$\begin{array}{c}\text { Puntaje general de capacidades no } \\
\text { verbales a los } 11 \text { años }\end{array}$} & \multirow[t]{2}{*}{5525} & Leve & 184 & NS \\
\hline & & Moderado/s evera & 73 & NS \\
\hline \multirow{2}{*}{$\begin{array}{c}\text { Altos logros educativos a } \\
\text { los } 33 \text { años }\end{array}$} & \multirow[t]{2}{*}{4965} & Leve & 184 & NS \\
\hline & & Moderado/s evera & 65 & NS \\
\hline \multirow{2}{*}{$\begin{array}{c}\text { Empleo remunerado a los } 33 \text { años } \\
\text { (hombres) }\end{array}$} & \multirow[t]{2}{*}{2416} & Leve & 69/90 (77) & NS \\
\hline & & Moderado/s evera & $22 / 33(67)$ & NS \\
\hline \multirow{2}{*}{$\begin{array}{c}\text { Empleo remunerado a los } 33 \text { años } \\
\text { (mujeres) }\end{array}$} & \multirow[t]{2}{*}{2502} & Leve & $59 / 91(56)$ & NS \\
\hline & & Moderado/severa & $16 / 27(60)$ & NS \\
\hline \multirow{2}{*}{$\begin{array}{l}\text { Ningún deporte en el mes previo } \\
\text { (a los } 23 \text { años) }\end{array}$} & \multirow[t]{2}{*}{6592} & Leve & $117 / 237(49)$ & NS \\
\hline & & Moderado/s evera & $41 / 82(50)$ & NS \\
\hline \multirow{2}{*}{$\begin{array}{c}\text { No haber ido a bailar en el mes } \\
\text { previo (a los } 23 \text { años) }\end{array}$} & \multirow[t]{2}{*}{6592} & Leve & $101 / 238$ (42) & NS \\
\hline & & Moderado/s evera & $33 / 82(40)$ & NS \\
\hline \multirow{2}{*}{$\begin{array}{c}\text { No haber ido al cine en el mes } \\
\text { previo (a los } 23 \text { años) }\end{array}$} & \multirow[t]{2}{*}{6598} & Leve & $150 / 238(63)$ & NS \\
\hline & & Moderado/s evera & $49 / 82(60)$ & NS \\
\hline \multirow{2}{*}{$\begin{array}{l}\text { Autoreporte de mala salud } \\
\text { (a los } 33 \text { años) }\end{array}$} & \multirow[t]{2}{*}{3579} & Leve & 121 & NS \\
\hline & & Moderado/s evera & 51 & NS \\
\hline \multirow{2}{*}{$\begin{array}{l}\text { Depresión a los } 33 \text { años (consulta } \\
\text { en los } 10 \text { años previos }\end{array}$} & \multirow[t]{2}{*}{3578} & Leve & $21 / 120(18)$ & NS \\
\hline & & Moderado/s evera & $8 / 50(16)$ & NS \\
\hline \multirow[t]{2}{*}{ Accidentes automovilísticos } & \multirow[t]{2}{*}{5390} & Leve & $39 / 200(20)$ & NS \\
\hline & & Moderado/severa & $22 / 72(31)$ & $2,33(1,29$ a 4,20$)$ \\
\hline
\end{tabular}

*Ajustado por clase social, sexo, edad, tamaño familiar, estrabismo, tratamiento por ambliopía.

\section{Conclusión}

Es muy difícil distinguir a nivel poblacional, entre las vidas de las personas con y sin ambliopía en base a varios indicadores importantes.

Fuente de financiamiento: Fundación BUPA

\section{Comentario}

La ambliopía es la causa más común de pérdida visual irreversible y prevenible en los niños, con una prevalencia entre un 2 y $7 \%^{1,2}$. Es el resultado de otra patología ocular sobre el desarrollo de la vía visual - generalmente defectos refractarios o estrabismo. A partir de investigaciones clínicas y experimentales que indicaban mejores resultados en aquellos que recibían tratamiento precoz, el rastreo de estrabismo y otras alteraciones visuales que pueden producir ambliopía comenzaron a ser fuertemente recomendado en varios países. ${ }^{2}$ En el Reino Unido a partir del programa nacional ${ }^{3}$ que incluye el rastreo masivo de estas alteraciones en niños de 4 a 5 años, comenzó a debatirse sobre el verdadero valor del mismo en parte reflejando la escasa evidencia sobre las consecuencias funcionales que la ambliopía podía producir y el impacto de las mismas en la población general.

Éste estudio, con un diseño adecuado para este tipo de evaluaciones, explora a nivel poblacional, diferentes indicadores que dan cuenta de las vidas de las personas con y sin ambliopía sin encontrar diferencias significativas. Para clasificar la ambliopía se tuvieron en cuenta el interrogatorio a los padres y las evaluaciones por parte de examinadores médicos generales lo que pudo haber provocado sesgos* en la clasificación de ambliopía. A pesar de ello, tuvieron un prevalencia de $1,2 \%$ de ambliopía moderada a severa, lo que coincide con estudios previos en esos países. ${ }^{4}$
Los dos fundamentos principales esgrimidos últimamente en estos países para justificar el rastreo son: la exclusión laboral y el riesgo de incapacidad visual debido a la pérdida de visión en el ojo sano. En el Reino Unido este último riesgo es en la vida entre el 1 y $3 \% .^{5}$ Si bien es importante, es algo muy poco prevalente como para justificar un rastreo en población general.

La escasa literatura sobre las limitaciones laborales asociadas con ambliopía $^{6}$, y sus implicancias para el crecimiento socioeconómico individual sugiere que tiene poco impacto sobre la clase laboral, y en este sentido, este estudio también refuerza este concepto. Desconocemos la aplicabilidad de estos hallazgos a otras sociedades.

\section{Conclusiones del comentador}

A pesar del aporte que este estudio brinda, se requieren nuevas investigaciones que permitan conocer más sobre la naturaleza y gravedad de la incapacidad que podría producir la ambliopía, y cuánto se mejoraría con el tratamiento precoz como para poder caracterizar mejor la importancia desde la salud pública, que todavía permanece escasamente conocida. Por otra parte, debemos ser muy cautos con los resultados por las diferencias que nuestra población puede tener con la población de la cohorte británica.

Mara Cecilia Vallese [ Médica Especialista en Medicina Familiar de Construir Salud, Centro Privado de Medicina Familiar y Trinidad Medical Center. ] Vallese MC. La ambliopía no afectaría el funcionamiento social, la educación, ni la salud. Evid. actual. práct. ambul. 9(5) ;142. Sep - Oct. 2006. Rahi JS, Cumberlando de PM, peckham CS. Does amblyopia affect educational, health and social outcomes? Findings from 1958 British birth cohort. BMJ 2006;332:820-5. PMID: 16520328

Referencias

1. Tenaglia R. Ambliopía: su pesquisa en la escuela. Arch Arg Pediatr 2002;100(4):342-4.

2. Vallese MC. Rastreo de ambliopía en niños: Evid actual práct ambul 2004 mayo-junio Vol 7 Nro. 3:80-5.

3. National Child Development Study, 2004.www.cls.ioe.ac.uk/studies.asp?section =000100020003 (accessed 14 Feb 2006).

4. Williams C, Northstone K, Harrad R, Sparrow JM, Harvey I, ALSPAC Study Team. Amblyopia treatment outcomes after screening before or at age 3 years: follow up from randomised trial. BMJ 2002;324:1549-51.

5. Rahi JS, Cumberland PM, peckham CS. Does amblyopia affect educational, health and social outcomes? Findings from 1958 British birth cohort. BMJ 2006;332:820-5. 6. Chua B, Mitchell P. Consequences of amblyopia on education, occupation, and long-term vision loss. Br J Ophthalmol 2004;88:1119-21. 